ORIGINAL ARTICLE

\title{
Nocturnal enuresis is a common complication following cardiac transplantation
}

\section{H Leonard, N Plant}

See end of article for authors' affiliations .....................

Correspondence to: Dr H Leonard, Royal Victoria Infirmary, Newcastle upon Tyne NEI 4LP, UK helen.leonard@lineone.net

Accepted 18 April 2003

Aims: To investigate the incidence of nocturnal enuresis post-cardiac transplantation. Methods: Seventy two cardiac transplantations have been performed in children under 16 years of age. All recipients who were alive and over 4 years of age at the time of the study received a questionnaire about urinary symptoms; 54 of the 57 eligible children participated.

Results: Twenty five children had persistent nocturnal enuresis post-transplantation. Thirteen of them had previously attained reliable night-time dryness but developed secondary nocturnal enuresis following transplantation, with three subsequently regaining dryness at ages 8,12 , and 17 years; 10 were still wetting mean age 12.3. Twelve children had not achieved night-time dryness when transplanted (all were under 4 years of age at the time) and continued to wet. Only one of these children achieved dryness (at age 12 using oxybutynin); the other 11 remained wet at night at a mean age of 9.3 years. Twenty nine children were dry at night post-transplantation, but 21 of them had nocturia at least three times a week. There is a significant difference in age at transplantation between the primary nocturnal enuretic children (mean age 2.0) and the secondary nocturnal enuretic children (mean age 7.4) as well as between the primary nocturnal enuretic children and the non-enuretic children (mean age 9.0).

Conclusions: Transplanting young children frequently delays the normal attainment of night-time continence or causes them to start wetting again. It should not be dismissed as a minor problem as it causes low self-esteem and is socially limiting. It is important families are aware it is a direct result of the transplantation process.

M any complications of paediatric cardiac transplantation are well recognised. These include rejection, posttransplantation coronary disease, and side effects of immunosuppressive drugs such as infection, post-transplantation lymphoproliferative disease, renal impairment, and hirsuitism. $^{12}$

We report primary and secondary nocturnal enuresis as common complications following paediatric cardiac transplantation. They have not previously been described.

\section{METHODS}

\section{Patient population}

We transplanted 72 children under 16 years of age between the start of our cardiac transplantation programme in October 1985 and 1999. There were 11 deaths prior to the start of this study. Four children were excluded as they were under 4 years of age at the time of study and would not be expected to have attained nocturnal continence. Fifty four of the remaining 57 children participated in the study.

Children were treated with a maintenance immunosuppressive regimen of cyclosporin and azathioprine, which has been described in detail elsewhere. ${ }^{3}$

No children had significant neurodevelopmental delay (all were at mainstream school in age appropriate year). No children were taking maintenance diuretics, although most were treated with diuretics in the first month posttransplantation. Urinary infection was excluded by urinalysis (dipstick and microscopy if dipstick was positive).

\section{Data collection}

A questionnaire was sent to parents of all children eligible for the study. Definitions of nocturnal enuresis vary. We used a popular definition of children who had involuntary voiding of urine on at least one night a week. ${ }^{4}$

\section{Statistics}

An unpaired $t$ test was used to compare age at transplantation of the primary enuretic, secondary enuretic, and nonenuretic children.

\section{RESULTS}

\section{Primary nocturnal enuretics}

Twelve children were not dry at night at time of transplantation; their mean age at transplantation was 2.0 years (range 0.2-3.9). Only one child had attained night-time dryness following transplantation at age 12 years. The other 11 remain wet at night at a mean age of 9.3 years (range 4.7 12.8). Only two of them are still less than 7 years old.

\section{Secondary nocturnal enuretics}

Thirteen children were reliably dry when transplanted and subsequently restarted wetting. All children who restarted wetting did so within a month of transplantation. Their mean age at transplantation was 7.3 years (range 2.3-14.1). Three children have regained night-time continence at ages 8, 12, and 17 respectively, but the other 10 remain enuretic with a mean age of 12.3 years (range 4-19.6). Only one of them is less than 7 years old.

\section{Non-enuretics}

Twenty nine of the 54 children in the study had not experienced problems with enuresis. Their mean age at transplantation was 9.0 years (range 0.4-15.6).

There is a statistically significant difference $(\mathrm{p}<0.001)$ in age at transplantation between the primary nocturnal enuretic children and the secondary nocturnal enuretic children, as well as between the primary nocturnal enuretic children and the non-enuretic children $(p<0.001)$. There was no statistically significant difference in age at transplantation 
between the secondary nocturnal enuretic and non-enuretic children.

\section{Frequency of enuresis}

Of the 21 children currently wetting, 13 children had nocturnal enuresis every night, two at least three times a week, and six once or twice a week.

\section{Nocturia}

Twenty nine children had not experienced problems with enuresis. However, 27 of these children had nocturia, with 21 waking to void at least three times a week. There is a statistically significant difference $(p<0.001)$ in age at transplantation between the primary nocturnal enuretic children and the children with nocturia, but not between the secondary nocturnal enuretic children and the children with nocturia.

\section{Family history}

Three children (all primary nocturnal enuretics) had a family history of nocturnal enuresis in parents or siblings. None of the others reported a positive history in any family members.

\section{Associated symptoms}

Two girls (one primary enuretic and one non-enuretic) reported daytime urgency, but no child had a problem with daytime enuresis. One child had a history of soiling, although they were not enuretic.

\section{Diagnosis at transplantation}

Thirty three children were transplanted because of cardiomyopathy, and 21 with congenital heart disease (table 1).

\section{DISCUSSION}

The incidence of nocturnal enuresis in otherwise healthy children has been reported as $15 \%$ at 5 years of age with a spontaneous resolution frequency of $15 \%$ a year. ${ }^{5}$ By age 7 , around $90 \%$ of well children are dry at night. ${ }^{67}$ Our study reveals a high incidence of nocturnal enuresis post-cardiac transplantation, with $46 \%(25 / 54)$ of children in the study being wet at night. Only $16 \%(4 / 25)$ of the nocturnal enuretics have subsequently become dry, and this has been achieved late at $8,12(2)$, and 17 years of age. The remaining 21 children still have a problem with bedwetting well beyond an age when they would be expected to be dry at night (only three are presently under 7 years of age).

The reasons for the high incidence in the study group are uncertain, particularly as the pathophysiology of nocturnal enuresis in otherwise healthy children is complex. There is often a strong family history and genetic component. ${ }^{8-10}$ This does not appear to be the case with the post-transplantation nocturnal enuretics and other mechanisms must be responsible.

A tendency to nocturnal polyuria ${ }^{11}{ }^{12}$ and poor urine concentrating ability ${ }^{13}$ has been noted in nocturnal enuretics. Nocturnal enuretics tend to have higher urine production on wet nights. ${ }^{14}$ This may be due to disturbances of the normal

Table 1 Diagnosis at transplantation

\begin{tabular}{lcc}
\hline & Cardiomyopathy & $\begin{array}{l}\text { Congenital heart } \\
\text { disease }\end{array}$ \\
\hline $\begin{array}{l}\text { Non-enuretic } \\
\text { Primary nocturnal }\end{array}$ & 22 & 7 \\
$\begin{array}{l}\text { enuretic } \\
\text { Secondary nocturnal } \\
\text { enuretic }\end{array}$ & 5 & 6 \\
Total & 33 & 8 \\
\hline
\end{tabular}

diurnal variation in vasopressin ${ }^{6}{ }^{15} 16$ or atrial natriuretic peptide levels. ${ }^{17}$ Enuretics also are reported to have a reduced functional bladder capacity compared to healthy controls. ${ }^{18}$ Functional bladder capacity increases steadily with age and it is thought that enuresis occurs when the high volume of night-time urine production exceeds the functional bladder capacity. ${ }^{5}$

Cardiac transplantation recipients have abnormal cardiac and renal neuroendocrine reflexes, ${ }^{19}$ partly because the transplanted heart is denervated and partly because of the side effects of cyclosporin mediated via the autonomic nervous system. ${ }^{20}$ The majority of transplant recipients are hypertensive, often with the loss of diurnal variation in blood pressure. $^{2122}$ Differences in the release of vasopressin, ${ }^{23}$ hypersecretion of atrial natriuretic peptide, ${ }^{19}{ }^{24}$ and loss of the usual patterns of diurnal variation of atrial natriuretic peptide, rennin, and aldosterone $e^{25-27}$ have also been noted in cardiac transplant recipients.

It is likely that following cardiac transplantation there is loss of the normal diurnal variation in urine production. The resultant nocturnal polyuria causes nocturia in older children and adults and enuresis in younger children when functional bladder capacity is suddenly exceeded. A parallel situation has been described in newly diagnosed diabetics who start to wet the bed concomitantly with the development of polyuria. $^{28}$

Impaired renal function is common post-cardiac transplantation but is unlikely to contribute to the pathophysiology of nocturnal enuresis in this group, as the temporal association is wrong. The children with secondary enuresis restarted wetting within the first month post-transplantation. During this period renal function is well preserved and often better than pre-transplantation. ${ }^{29-31}$ Nocturnal enuresis is not a feature of impaired renal function in other circumstances; as overall renal function declines the volume of urine produced falls.

It is surprising that such a common complication has not been reported before. This may be because families think it is too trivial to inform the doctor about in comparison to their child's other medical problems. There may be embarrassment, especially with older children, so the information is not volunteered. People caring for paediatric cardiac transplant recipients should ask specifically about nocturnal enuresis and discuss this complication during pre-transplantation counselling. It is very important to inform the family that nocturnal enuresis is a direct result of the transplantation process to avoid the child being "blamed" for the wetting. They should also be reassured that nocturnal enuresis is not due to psychological problems. ${ }^{10}{ }^{32}{ }^{33}$ Although it may not be regarded as a serious or life threatening medical problem, the impact on children and their families must not be underestimated. For the child, it adds to low self esteem, is socially limiting, can aggravate skin problems caused by cyclosporin, and reinforces that a child with a transplant is different from their peers. Nocturnal enuresis also has economic and social implications for the rest of the family, ${ }^{34}$ adding to the burden of looking after a child with a cardiac transplant.

\section{APPENDIX 1: SUMMARY OF QUESTIONNAIRE}

Current age: ...years ... months

Do you get up at night to go to the toilet?

- more than once a night

- every night

- almost every night

- 3 times a week or more

- 1-2 times a week

- less often 
Do you wet the bed? Yes/No

How often?

- every night

- almost every night

- 3 times a week or more

- 1-2 times a week

- once every couple of weeks

- once a month

- less often

Age when dry (out of nappies)

- During the day: ...years ...months OR ...not dry

- At night: ...years ...months OR ...not dry

If you were dry at night before the transplantation, did you start wetting the bed again afterwards? Yes/No

How old were you when you stopped again? ...years ...months

Bedwetting sometimes runs in families. Did anyone else in your family have problems with bedwetting?

- Yes - brothers or sisters

- Yes - parents

- No

If you tried any treatments for bedwetting:

- What was it called?

- Did it help ?

- No

- Helped a little

- Helped a lot

Any comments?

\section{Authors' affiliations}

H Leonard, Freeman Hospital, Newcastle upon Tyne NE7 7DN, UK

N Plant, Royal Victoria Infirmary, Newcastle upon Tyne NE1 4LP, UK

\section{REFERENCES}

1 Parameshwar J, Schofield P, Large S. Long term complications of cardiac transplantation. Br Heart J 1995;74:341-2.

2 Boucek MM Novick RJ, Bennett LE et al. The registry of the International Society of Heart and Lung Transplantation: Second official pediatric report1998. J Heart Lung Transplant 1998;17:1 141-60.

3 Leonard H, O'Sullivan JJ, Dark J. Long term surveillance after paediatric cardiac transplant; the role of endomyocardial biopsy. J Heart Lung Transplant 2000:19:469-72.

4 Butler RJ. Establishment of working definitions in nocturnal enuresis. Arch Dis Child 1991;66:267-71.

5 Alon US. Nocturnal enuresis. Pediatr Nephrol 1995:9:94-103.

6 Mark SD, Frank JD. Nocturnal enuresis. Br J Urol 1995:75:427-34

7 Hellstrom AL, Hanson E, Hanson S, et al. Micturition habits and incontinence in 7 year old Swedish school entrants. Eur J Paediatr 1990;149:434-7.
8 Arnell $\mathrm{H}$, Hjalmas $\mathrm{K}$, Jagervall $M$, et al. The genetics of primary nocturnal enuresis: inheritance and suggestion of a second major gene on chromosome 12q. J Med Genet 1997;34:360-5.

9 Von Gontard A, Hollman E, Eiberg H, et al. Clinical enuresis phenotypes in familial nocturnal enuresis. Scand J Urol Nephrol Suppl 1997;183:11-16.

10 Hallgren B. Enuresis: a clinical and genetic study. Acta Psychiatr Neurol Scand 1957;32(suppl 114):1-159.

11 Poulton ME. Relative nocturnal polyuria as a factor in nocturnal enuresis. Lancet 1952;ill:906-7.

12 Lackgren G, Neveus T, Stenberg A. Diurnal plasma vasopressin and urinary output in adolescents with monosymptomatic nocturnal enuresis. Acta Paediatr 1997:86:385-90.

13 Mevorach RA, Bogaert GA, Kogan BA. Urine concentration and enuresis in healthy preschool children. Arch Pediatr Adolesc Med 1995; 149:259-62.

14 Hansen AF, Jorgensen TM. A possible explanation of wet and dry nights in enuretic children. Br J Urol 1997;80:809-11.

15 Rittig S, Knudson UB, Jonler M, et al. Adult enuresis. The role of vasopressin and atrial natriuretic peptide. Scand J Urol Nephrol Suppl 1989; 125:79-86.

16 Rittig S, Knudson UB, Norgaard JP, et al. Abnormal diurnal rhythm of plasma vasopressin and urinary output in patients with enuresis. Am J Physiol 1989;256:F664-71

17 Norgaard JP, Pederson EB, Djurhuus JC. Diurnal anti-diuretic-hormone levels in enuretics. J Urol 1985;134:1029-31.

18 Starfeld B. Functional bladder capacity in enuretic and non enuretic children. J Pediatr 1967;70:777-81.

19 Braith RW, Mills RM, Wilcox CS, et al. Breakdown of blood pressure and body fluid homeostasis in heart transplant recipients. J Am Coll Cardiol 1996;27:375-83

20 Schererr U, Vissing SF, Morgan BJ, et al. Cyclosporine induced sympathetic activation and hypertension after heart transplantation. N Engl J Med 1990:323:748-50.

21 Jenkins GH, Singer DR. Hypertension in thoracic transplant recipients. J Hum Hypertens 1998; 12:813-23.

22 Idema RN, van den Meiracker AH, Balk AH, et al. Abnormal diurnal variation of blood pressure, cardiac output, and vascular resistance in cardiac transplant recipients. Circulation 1994;90:2797-803.

23 Perrault H, Melin B, Jimenez C, et al. Fluid-regulating and sympathoadrenal hormonal responses to peak exercise following cardiac transplantation. J Appl Physiol 1994:76:230-5

24 Kokot F, Religa Z, Pasyk S, et al. Atrial natriuretic peptide secretion in heart transplant patients. Int J Artif Organs 1989;12:321-6.

25 Cugini P, Lucia P, Scibila G, et al. Twenty four hour pattern of atrial natriuretic peptide in heart transplantation: evidence for lack of circadian rhythm. Temporal inter-relationships with plasma renin activity, aldosterone and cholesterol. Int J Cardiol 1993;42:7-14.

26 Sehested J, Thomas F, Thorn M, et al. Level and diurnal variation of hormones of interest to the cardiovascular system in patients with heart transplants. Am J Cardiol 1992:69:397-402.

27 Cugini P, Battista P, Di Palma L, et al. Secondary aldosteronism documented by plasma renin and aldosterone circadian rhythm in subjects with kidney or heart transplantation. Renal Failure 1992;14:69-76.

28 Alon U, Woodward V, Howard CP. Urine volume, age and nocturnal enuresis: a prospective study on newly diagnosed children with diabetes mellitus. Child Hosp Q 1992;4:157-60.

29 Hornung TS, de Goede C, O'Brien C, et al. Renal function after pediatric cardiac transplantation: the effect of early cyclosporin dosage. Pediatrics 2001; 107:1346-50.

30 Ruggenenti P, Perico N, Amuchastegui CS, et al. Following an initial decline, glomerular filtration rate stabilises in heart transplant patients on chronic cyclosporin. Am J Kidney Dis 1994:24:549-53.

31 Hartmann A, Andereassen AK, Holdaas H, et al. Five years' follow-up of renal glomerular and tubular functions in heart transplant recipients. $J$ Heart Lung Transplant 1996:15:972-9.

32 Wille S, Anveden I. Social and behavioural perspectives in enuretics, former enuretics and non-enuretic controls. Acta Paediatr 1995;84:37-40.

33 Baker LB. Symptom treatment and symptom substitution in enuresis. J Abnorm Psychol 1969:74:42-9.

34 Schulpen TW. The burden of nocturnal enuresis. Acta Paediatr 1997:86:981-4 